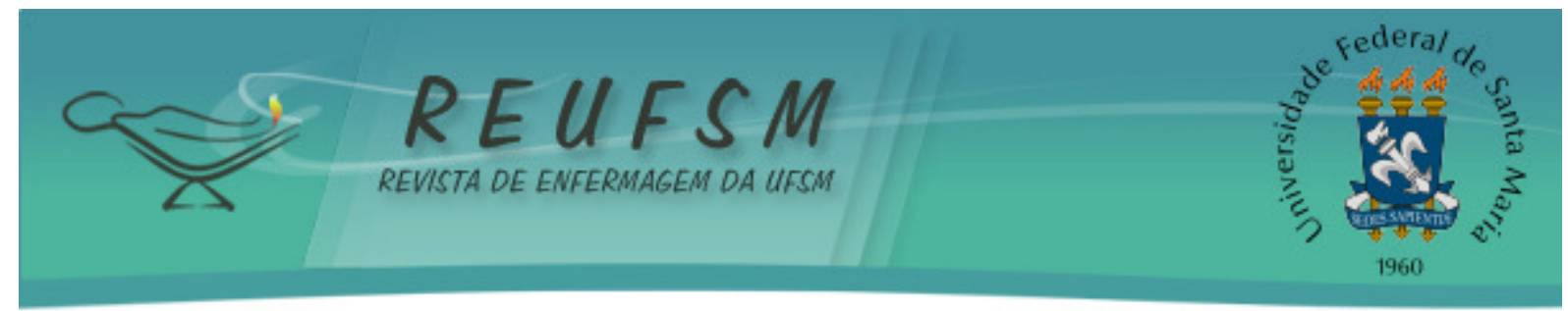

ARTIGO DE REVISÃO

\title{
PRODUÇÃO CIENTÍFICA SOBRE A ENFERMAGEM BRASILEIRA NA II GUERRA MUNDIAL: UM ESTUDO BIBLIOMÉTRICO
}

\author{
SCIENTIFIC PRODUCTION OF THE BRAZILIAN NURSING IN WORLD WAR II: A \\ BIBLIOMETRIC STUDY
}

\section{PRODUCCIÓN CIENTÍFICA DE LA ENFERMERÍA BRASILEÑA EN LA SEGUNDA GUERRA MUNDIAL: UN ESTUDIO BIBLIOMÉTRICO}

Luciana Mendes Berlofi ${ }^{1}$ Maria Cristina Sanna ${ }^{2}$

RESUMO: Objetivo: caracterizar a produção científica sobre História da Enfermagem brasileira e sua atuação profissional durante a Segunda Guerra Mundial. Método: estudo bibliométrico que empregou, como fontes documentais, pesquisas encontradas em busca realizada com descritores "História da Enfermagem" e "Il Guerra Mundial", nos bancos de dados LILACS, MEDLINE, PeriEnf e biblioteca virtual SciELO. Com apoio de planilha eletrônica, foram realizados cálculos da frequência simples e relativa das variáveis: indexação, idioma, autores, descritores, veículo de publicação, ano, método, vinculação acadêmica, categorização temática. Resultados: encontradas 15 pesquisas com participação de 11 autores. "História da Enfermagem" foi o descritor mais empregado, 73,3\% dos estudos referem-se à História das Instituições. Conclusões: apesar das instituições de pesquisa situadas no Rio de Janeiro serem polo de estudos mais produtivo sobre a temática, ainda existem lacunas de conhecimento sobre a atuação da Enfermagem brasileira durante a II Guerra Mundial.

Descritores: Enfermagem; História da enfermagem; II Guerra mundial; Bibliometria; Brasil.

ABSTRACT: Objective: characterize the scientific production about the history of brazilian nursing and its professional performance during World War II. Method: bibliometric study which employed, as documentary sources, research found in a search using the descriptors "History of Nursing" and "World War II" at LILACS, SciELO, Medline, PeriEnf. Supported by electronic spreadsheet, were performed on simple and relative frequency the following variables: indexing, language, author, descriptors, vehicle of publication, year, method, academic affiliation, classification. Results: found 15 items with the participation of 11 different authors. "History of Nursing" was the most employed descriptor and $73.3 \%$ of the studies were related to history of institutions. Conclusions: despite research institutions located in Rio de Janeiro are the most productive pole of studies on the subject, there are still gaps in knowledge about the performance of Brazilian Nursing during World War II. Descriptors: Nursing; History of nursing; World war II; Bibliometrics; Brazil.

RESUMEN: Objetivo: caracterizar la producción científica sobre la historia de la Enfermería brasileña y su desempeño profesional durante la Segunda Guerra Mundial. Método: estudio

\footnotetext{
${ }^{1}$ Enfermeira do Hospital Alemão Oswaldo Cruz. MBA Executivo em Gestão em Saúde. Mestranda do Programa de Pós-graduação Senso Estrito da Escola de Enfermagem da Universidade Federal de São Paulo (EPE-UNIFESP). Membro do Grupo de Estudos e Pesquisa em Administração em Saúde e Gerenciamento em Enfermagem (GEPAG) da EPE-UNIFESP. E-mail: luberlofi@bol.com.br

2 Enfermeira. Doutora em Enfermagem. Pesquisadora Independente. Professora Afiliada e Orientadora Credenciada do Programa de Pós-graduação Senso Estrito da EPE- UNIFESP. Pesquisadora do Grupo de Estudos e Pesquisa em Administração em Saúde e Gerenciamento em Enfermagem (GEPAG) da EPE-UNIFESP. E-mail: mcsanna@uol.com.br
} 


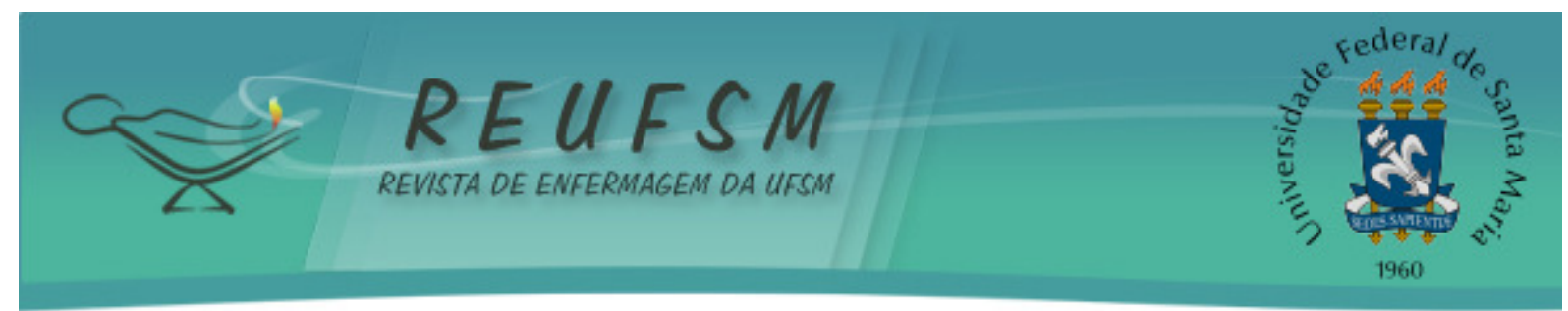

bibliométrico que empleó, como fuentes documentales, estudios encontrados en búsqueda con las palabras clave "Historia de Enfermería" y "Segunda Guerra Mundial" en la base de datos LILACS, SCIELO, MEDLINE, PeriEnf. Fueron realizados cálculos de la frecuencia simple y relativa de las variables: indexación, idioma, autores, descriptores, publicación de vehículo, año, método, vinculación académica, categorización temática. Resultados: encontraron 15 estudios con participación de 11 autores. "Historia de la Enfermería", fue el descriptor más empleado, el 73,3\% de los estudios se refieren a historia de las instituciones. Conclusiones: a pesar de las instituciones de investigación localizadas en Río de Janeiro ser el polo más productivo sobre el tema, todavía hay huecos del conocimiento sobre el desempeño de la enfermería brasileña durante la Segunda Guerra Mundial.

Descriptores: Enfermería; Historia de la enfermería; Segunda Guerra Mundial, Bibliometría; Brasil.

\section{INTRODUÇÃO}

A profissionalização da Enfermagem no Brasil teve como importante marco, o ano de 1890 com a criação, na cidade do Rio de Janeiro, da Escola de Enfermeiros e Enfermeiras do Hospício Nacional de Alienados, atualmente Escola de Enfermagem Alfredo Pinto, que adotava o modelo francês de ensino. Apesar da existência de experiência paulistana anterior com a Escola do Hospital Samaritano essa, entre outros atributos, destacou-se por ser uma escola oficial. ${ }^{1}$

No início do século XX, a Enfermagem brasileira sofreu forte influência da estrutura norte-americana de atenção à saúde, por meio da Missão de Cooperação Técnica para o Desenvolvimento da Enfermagem no Brasil, também conhecida por "Missão Parsons", que instalou a primeira escola do modelo Nightingaleano no país, hoje, Escola de Enfermagem Anna Nery - EEAN."I A Fundação Rockfeller foi a instituição responsável por concretizar tais ações de desenvolvimento, e teve papel decisivo na transformação da Enfermagem Moderna no país. ${ }^{2} \mathrm{~A}$ influência do modelo anglo-americano acabou, então, por se tornar hegemônica.

Também é importante lembrar que a Enfermagem profissional, assim configurada, se firmou no Brasil atrelada às políticas públicas que privilegiavam a assistência médicohospitalar já que, na primeira metade do século XX, o desenvolvimento da profissão de enfermeiro e as relações de saber e poder que a permeiam, foram construídas a partir das transformações na sociedade brasileira, bem como em seus hospitais. ${ }^{3}$

A substituição do cuidado baseado em conhecimento empírico por um saber científico legitimou a profissão de enfermeiro. Tal legitimidade se tornou visível em momento estratégico da história política e social do Brasil quando, em 1930, Getúlio Vargas tornou-se o presidente da república e implantou a ditadura varguista, com a consolidação do Estado Novo, marcado por suas políticas populistas de Trabalho, Educação e Saúde. No período historicamente conhecido como Era Vargas, a Enfermagem Brasileira, alcançou um de seus momentos mais marcantes, no que diz respeito à procura pela profissão de enfermeiro. ${ }^{4}$ Foi também durante o Estado Novo que o Ministério do Trabalho, Indústria e Comércio regulamentou o trabalho das mulheres o que, além de fortalecer a emancipação da mulher, contribuiu para a sua reconfiguração na sociedade brasileira. ${ }^{5}$

Além disso, a expansão da comunicação através de jornais, revistas, cinemas e telefone, favoreceram o rompimento da imagem feminina tradicional e a estruturação de uma nova ordem social. A mulher, então, buscou conquistar espaço na vida pública em que se evidenciou a oportunidade de visibilidade para as profissões ditas femininas, com destaque para as de enfermagem. ${ }^{5}$ Esse era o cenário em que a Enfermagem brasileira estava inserida, quando, no fim da década de 1930 eclodiu a II Guerra Mundial (1939-1945). 


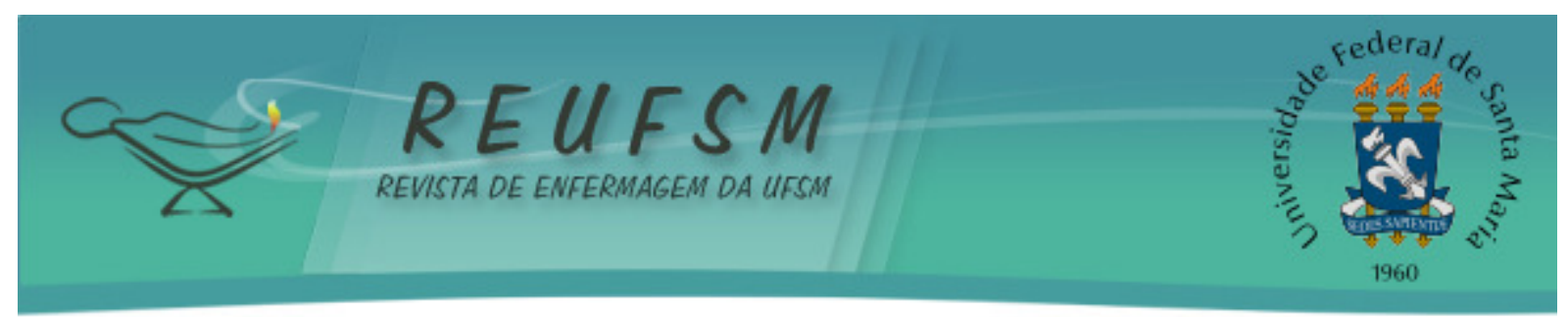

Existia a necessidade não só de recrutar, mas também de preparar enfermeiros que pudessem atuar na ocasião de combate no Brasil ou no exterior. Não se sabia ao certo qual seria a atuação da Enfermagem brasileira na II Guerra Mundial; a única certeza era que não se dispunha de profissionais suficientes para atuação de tal tamanho. Atenta a essa necessidade, a Cruz Vermelha que estava vinculada ao Ministério da Guerra, mobilizou seus esforços no desenvolvimento de profissionais na capital paulista. Os cursos de formação em enfermagem tiveram uma significativa procura, ocorrendo de forma espontânea, porém reforçadas pela influência das propagandas do governo brasileiro que, em discurso persuasivo, projetava a profissão como a imagem de pátria mãe. ${ }^{6}$

Em 1944, foi enviado, para a Itália, um grupo de 67 "enfermeiras" junto à Força Expedicionária Brasileira (FEB) e seis junto à Força Aérea Brasileira (FAB). Todas elas se voluntariaram para essa missão e concluíram o Curso de Enfermeiras da Reserva do Exército. Foram as primeiras mulheres a ingressar no serviço ativo das Forças Armadas no país, mas somente oito eram enfermeiras oficialmente reconhecidas como tal pela legislação federal e uma era parteira. ${ }^{7}$

Assim como em outras culturas, o reconhecimento e a ascensão da Enfermagem estão atrelados a momentos históricos de guerra e à disputa de interesses sociopolíticos. 0 período histórico e político da II Guerra Mundial, vivenciada no Brasil em meio à Ditadura do Estado Novo, foi um momento marco para o desenvolvimento e o reconhecimento da profissão pela sociedade brasileira, sobre o que alguns pesquisadores tem se debruçado. ${ }^{4-19}$

0 objeto de estudo desta pesquisa é a produção científica escrita e publicada em português sobre a História da Enfermagem brasileira e sua atuação profissional durante a II Guerra Mundial. Pretende-se caracterizar esse conjunto de obras por meio de uma avaliação predominantemente quantitativa, além de entender quais os principais assuntos de interesse dos estudos, identificando as lacunas de produção intelectual a serem preenchidas. A justificativa para a realização desse estudo está pautada na sua contribuição para posteriores pesquisas históricas no campo da Enfermagem, além de se somar aos conhecimentos existentes, favorecendo a visibilidade dessa área profissional.

\section{MÉTODO}

A bibliometria surgiu no início do século XX como sintoma da necessidade do estudo e da avaliação das atividades de produção e comunicação científica. Utiliza-se mais dos métodos quantitativos do que discursivos, na busca por uma avaliação objetiva da produção científica. Dessa forma, a bibliometria é um dos melhores métodos para a promoção do controle bibliográfico, ou seja, conhecer o tamanho e as características dos acervos, bem como elaborar previsões de crescimento. É utilizada como técnica quantitativa e estatística de medição dos índices de produção e disseminação do conhecimento científico. ${ }^{20}$ Assim, o presente trabalho é um estudo descritivo desenvolvido na perspectiva bibliométrica.

A busca pela produção científica referente ao tema em estudo foi realizada nos seguintes acervos: Literatura Latino-americana e Caribe em Saúde (LILACS), Scientific Electronic Library Online (SciELO), Medical Literature Analysis and Retrieval System Online (MEDLINE) e Base de Dados Eletrônica sobre Periódicos Nacionais da Biblioteca da Escola de Enfermagem da Universidade de São Paulo - EEUSP (PeriEnf).

A pesquisa foi realizada em abril de 2012 e nela foram empregados os descritores indicados pelo DeCS, "História da Enfermagem" e "Il Guerra Mundial" que foram comutados concomitantemente. Experiências pregressas utilizando os descritores separadamente resultaram em indicações imprecisas e muito volumosas, razão pela qual tais resultados foram descartados, preferindo-se a estratégia da utilização simultânea dos descritores. 


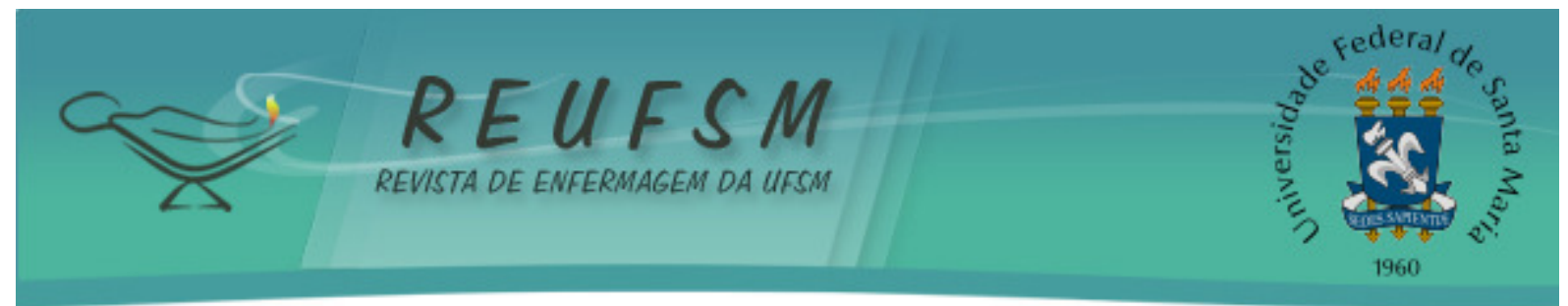

Foram critérios de inclusão: que os textos fossem indicados pela biblioteca virtual e bancos de dados consultados, estivessem disponíveis em formato eletrônico, fossem passíveis de recuperação na forma integral, fossem escritos em português e versassem sobre a Enfermagem brasileira na II Guerra Mundial. Os documentos que não se enquadraram nesses critérios foram excluídos.

A coleção de indicações da biblioteca virtual e dos bancos de dados consultados foram, então, cotejadas entre si e excluídas as indicações repetidas. Constituiu-se um total de 15 trabalhos. Na Tabela 1, pode-se apreciar o número de indicações obtidas na busca a cada um dos acervos consultados (bancos de dados e biblioteca virtual) e as indicações repetidas, tendo-se tomado o SciELO como guia.

Tabela1. Distribuição de indicações de publicações nos bancos de dados e na biblioteca virtual para a consulta concomitante dos descritores "História da Enfermagem" e "II Guerra Mundial”, São Paulo, 2012.

\begin{tabular}{lcccc}
\hline \multirow{2}{*}{ Publicação Indicada } & \multicolumn{4}{c}{ Acervos } \\
\cline { 2 - 5 } & SciELO & LILACS & Medline & PeriEnf \\
\hline Referência 4 & - & - & - & $\mathrm{x}$ \\
Referência 6 & $\mathrm{x}$ & - & - & - \\
Referência 7 & $\mathrm{x}$ & - & - & - \\
Referência 8 & $\mathrm{x}$ & $\mathrm{x}$ & $\mathrm{x}$ & - \\
Referência 9 & - & $\mathrm{x}$ & $\mathrm{x}$ & - \\
Referência 10 & - & $\mathrm{x}$ & - & - \\
Referência 11 & $\mathrm{x}$ & $\mathrm{x}$ & - & - \\
Referência 12 & $\mathrm{x}$ & $\mathrm{x}$ & $\mathrm{x}$ & - \\
Referência 13 & - & $\mathrm{x}$ & - & $\mathrm{x}$ \\
Referência 14 & - & $\mathrm{x}$ & - & $\mathrm{x}$ \\
Referência 15 & $\mathrm{x}$ & - & - & - \\
Referência 16 & $\mathrm{x}$ & - & - & - \\
Referência 17 & $\mathrm{x}$ & - & - & - \\
Referência 18 & - & - & - & $\mathrm{x}$ \\
Referência 19 & - & - & - & $\mathrm{x}$ \\
\hline Total de indicação (acervos) & $\mathbf{8}$ & $\mathbf{7}$ & $\mathbf{3}$ & $\mathbf{5}$ \\
\hline
\end{tabular}

Legenda: "X" significa que a publicação foi indicada, e "_" que a publicação não foi indicada nos acervos (biblioteca virtual e bases de dados).

Com auxílio de planilha eletrônica construída com ferramenta Excel $®$, elaborou-se, então, um banco de dados com as seguintes variáveis: indexação em acervo (banco de dados e biblioteca virtual), idioma do texto, nome dos autores, descritores, veículo de publicação, ano, método da pesquisa, vinculação acadêmica dos autores e categorização temática. A construção desse banco de dados objetivou facilitar e organizar a análise das informações levantadas de cada produção, permitindo que cada variável tivesse os cálculos de frequência simples e relativa realizados.

Para a última parte da pesquisa, as produções científicas foram segmentadas, segundo a categorização proposta em estudo específico ${ }^{21}$, que é a análise temática mais sensível que se tem da área abordada. Tal categorização propõe a organização da produção intelectual sobre História da Enfermagem em três eixos temáticos: “Antropologia 


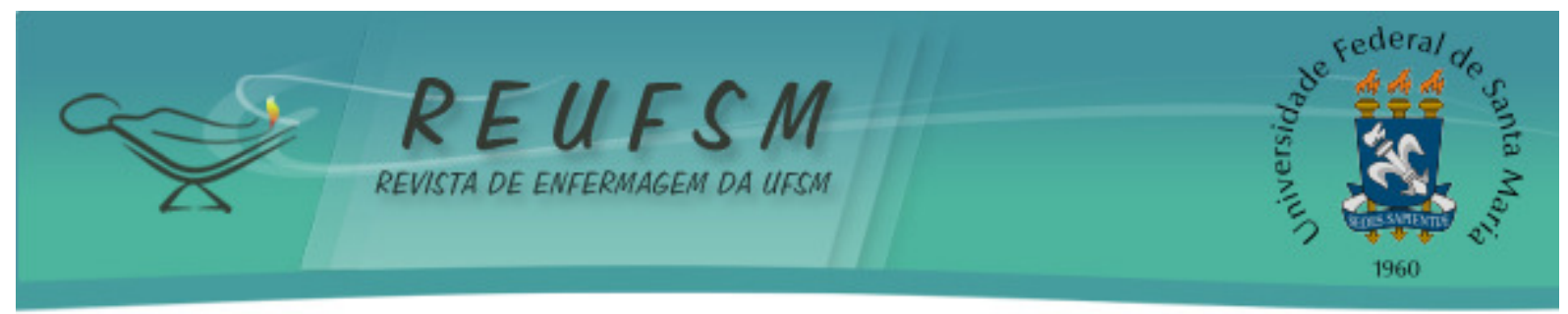

do cuidado", "História das instituições de ensino, de assistência e agremiações de enfermagem" e "História de vida".

O eixo temático "Antropologia do cuidado" ressalta o cuidado como produto da reflexão sobre ideias e ações relacionadas ao processo das necessidades de saúde do indivíduo, garantindo integridade e harmonia de todas as etapas que constituem a vida humana.

0 eixo "História das instituições de ensino, de assistência e agremiações de enfermagem" abrange os trabalhos em torno de movimentos sociais considerados no âmbito da formação profissional (como a criação de escolas e postos de trabalho), das demandas político-associativas (formação e manutenção dos órgãos de classe como ABEn, COFEN e COREN), e congêneres.

Já o eixo "História de vida" segmenta os estudos interessados em biografia, da micro história e do resgate das memórias individuais, ou seja, se referem a agentes históricos que construíram a história da enfermagem.

\section{RESULTADOS E DISCUSSÃO}

Identificou-se a participação de onze diferentes autores, sendo que a maior contribuição foi de Tânia Cristina Franco Santos (professora titular da Escola de Enfermagem Anna Nery - Universidade Federal do Rio de Janeiro), com participação em nove $e^{4,8,11,13,14-17,19}$ estudos analisados. Na sequencia estão Gertrudes Teixeira Lopes (professora titular do Departamento de Fundamentos de Enfermagem da Faculdade de Enfermagem da Universidade do Estado do Rio de Janeiro) e Margarida Maria Rocha Bernardes (professora auxiliar da Universidade Estácio de Sá - Rio de Janeiro) contribuindo respectivamente com oito ${ }^{4,9,12-16,19}$ e sete ${ }^{4,9,12-15,19}$ publicações. Diante desses dados, é possível afirmar que, atualmente, as três autoras citadas são as estudiosas que mais pesquisam sobre a história da enfermagem brasileira durante a II Guerra Mundial. Ressaltase que muitas publicações foram feitas em regime de co-autoria e que, foi contada uma inserção para cada autor citado na publicação.

Interessante achado foi o de aproximadamente $85 \%$ das produções científicas terem sido produzidas por pesquisadores fluminenses e quase a metade deste percentual, desenvolvidas no Núcleo de Pesquisa de História da Enfermagem Brasileira (NUPHEBras), que congrega pesquisadores da Escola de Enfermagem Anna Nery e de outras instituições, principalmente, da cidade do Rio de Janeiro. Esse dado se harmoniza com o resultado acima mencionado sobre os principais responsáveis pela produção intelectual acerca do assunto estarem alocados na cidade do Rio de Janeiro. Outro fator de grande relevância é a participação, tanto de Tânia Cristina Franco Santos quanto de Gertrudes Teixeira Lopes, como membros no NUPHEBras, tendo sido, inclusive, dirigentes desse grupo.

Vale também comentar que um dos estudos ${ }^{7}$ foi desenvolvido no Departamento de História da Faculdade de Filosofia, Letras e Ciências Humanas da Universidade de São Paulo (FFLCH-USP), por um historiador doutor em História. O fato da representação e mobilização da enfermagem brasileira durante a II Guerra Mundial ter causado interesse em disciplinas que ultrapassem os campos da saúde, faz supor que a Enfermagem foi uma profissão marcante e estratégica durante o recorte temporal estudado.

Nos textos publicados foram utilizados como descritores, 25 diferentes vocábulos/expressões, com média de 4,2 unidades por resumo. "História da Enfermagem" foi citado 14 vezes, "II Guerra Mundial" sete vezes e "Enfermagem militar" oito vezes. Os três descritores representam $46 \%$ do total de descritores utilizados.

Quanto aos veículos de publicação, três artigos estão na "Escola Anna Nery Revista de Enfermagem"11,14,17, três artigos na revista "Texto \& Contexto em Enfermagem"6,15-16, dois artigos na "Revista Latino Americana de Enfermagem"4,8, dois artigos na "Revista 


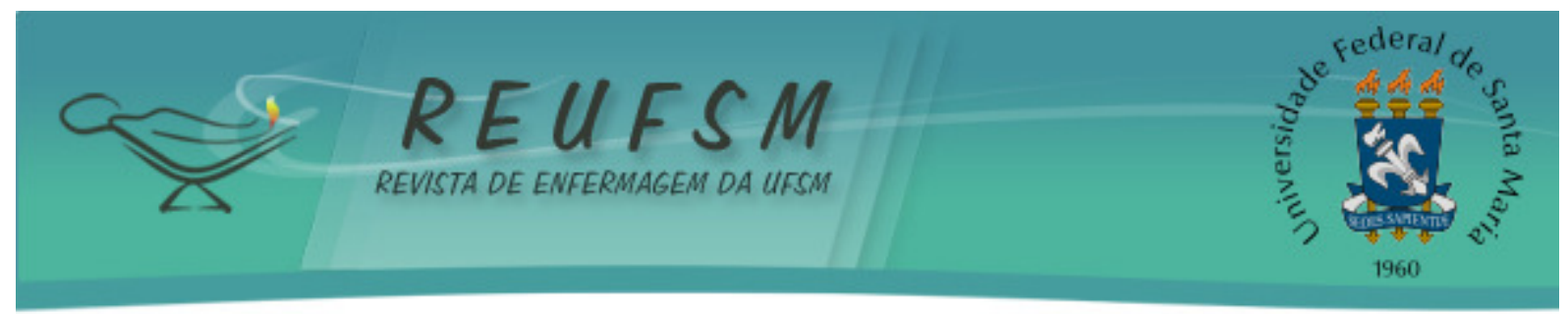

Escola de Enfermagem da USP"12-13, dois artigos na "Revista Brasileira de Enfermagem"9,18, um artigo na revista "História \& Ciências, Saúde, Manguinhos"7, um artigo na "Revista de Enfermagem da UERJ"19 e uma tese no Banco de Teses da Universidade Federal do Rio de Janeiro (defendida na EEAN). ${ }^{10}$

Apesar da produção sobre o assunto ser predominantemente oriunda do Estado do Rio de Janeiro, percebe-se que a publicidade desse conhecimento é dada em fontes diversas, de alcance nacional e internacional. Os produtos científicos são considerados atuais, pois a produção mais antiga é datada de $2000^{7}$ e a mais recente datada de $2010 .^{17}$ Ocorreu a concentração de quatro publicações no ano de 2007. ${ }^{9-12}$

Quanto ao método, a totalidade dos estudos foi classificada como histórico-social, que é o método mais comumente utilizado em pesquisas sobre História da Enfermagem. ${ }^{22}$ Percebese, em todos os estudos, a utilização de informações obtidas em fontes históricas primárias, complementadas com fontes secundárias. As fontes primárias variaram de fontes iconográficas a depoimentos orais, e incluíram também documentos escritos, observando-se a classificação proposta por Arostegui ${ }^{23}$ e conforme a indicação contida nos textos.

$\mathrm{Na}$ linha de pesquisa "História da Enfermagem" não existe uma categorização validada para a classificação dos estudos. A referência de maior relevância, conforme já mencionado, é a que segmenta a produção científica em três categorias: História das Instituições, Antropologia do Cuidado e História de Vida. ${ }^{21}$ Os textos estudados foram, então, classificados segundo essa diretiva, o que resultou no seguinte achado: $73,3 \%$ referem-se à História das Instituições ${ }^{6-7,10-12,14-19}, 20 \%$ à Antropologia do Cuidado ${ }^{4,9,13}$ e 6,7\% à História de $\mathrm{Vida}^{8}$, ficando patente a maior concentração na primeira categoria.

0 resultado demonstrou paridade ao encontrado por outra investigação ${ }^{21}$, quanto à prevalência de estudos no eixo temático "História das Instituições". Esse achado sugere maior interesse dos pesquisadores em evocar a memória de espaços de formação e trabalho, o que suscita o tema como um dos grandes núcleos de investigação no âmbito da história da enfermagem brasileira.

\section{CONCLUSÃO}

A análise dos 15 estudos que compõem a população pesquisada possibilitou desenhar os seguintes perfis: quantitativo expressivo da produção científica provem do Estado do Rio de Janeiro; os produtos das pesquisas foram divulgados em diversos periódicos, permitindo compartilhar tal produção em âmbito nacional, com incursão possível para o âmbito internacional, pois alguns desses veículos também são editados em inglês e espanhol; o método histórico-social é o mais empregado; o interesse pelo estudo do tema é recente; e existem, ainda, lacunas a serem pesquisadas.

Apesar da relevância das pesquisas analisadas no presente estudo, existem ainda lacunas no conhecimento sobre a atuação e a organização da Enfermagem brasileira durante a II Guerra Mundial, não só dos serviços de enfermagem organizados no front de batalha, mas, principalmente, sobre como os profissionais que permaneceram em território nacional enfrentaram esse período.

O Rio de Janeiro é, atualmente, considerado o maior polo de estudos sobre a Enfermagem brasileira na II Guerra Mundial. Isso se deve à atuação de destaque do NUPHEBras em pesquisas e publicações científicas sobre o tema. A atuação como docente naquele estado, das três principais pesquisadoras do assunto também pode ser considerada um fator facilitador na disseminação e no interesse pela temática.

Seguramente o quantitativo de publicações é pequeno frente às possibilidades que o tema permite considerar, o que, conforme os resultados aqui apresentados, pode estimular a realização de novas pesquisas. 


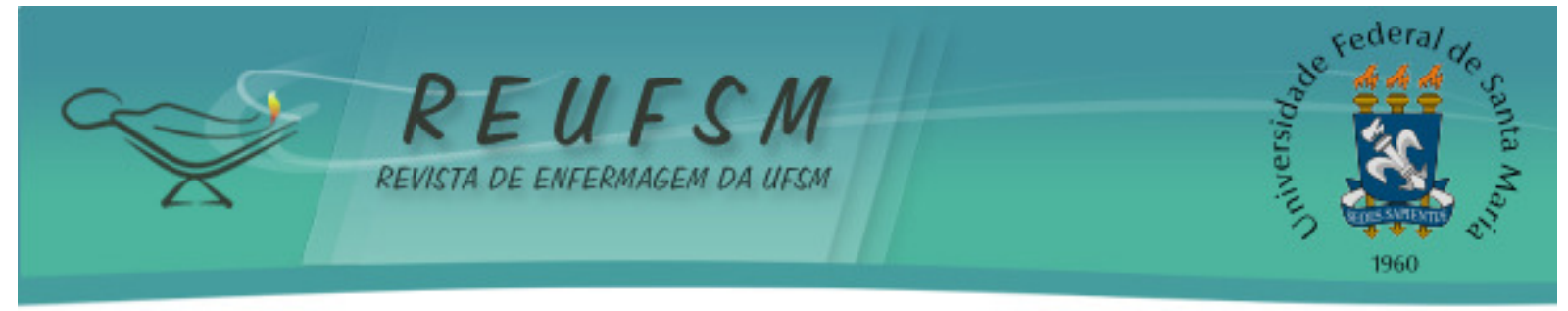

\section{REFERÊNCIAS}

1. Carrijo AR. Registros de uma prática: anotações de enfermagem na memória de enfermeiras da primeira escola nightingaleana no Brasil (1959-1970) [dissertação]. São Paulo: Universidade de São Paulo, Escola de Enfermagem; 2007. 143 p.

2. Kruse MHL. Enfermagem moderna: a ordem do cuidado. Rev Bras Enferm. 2006; 59(esp):403-10.

3. Padilha MICS, Sobral VRS, Leite LMR, Peres MAA, Araújo AC. Enfermeira - a construção de um modelo de comportamento a partir dos discursos médicos do início do século. Rev Latinoam Enferm. Ribeirão Preto. 1997 out;5(4):25-33.

4. Bernardes MMR, Lopes GT, Santos TCF. O cotidiano das enfermeiras do exército na Força Expedicionária Brasileira (FEB) no teatro de operações da $2^{\mathrm{a}}$ guerra mundial, na Itália (1942-1945). Rev Latinoam Enferm. 2005 maio/jun;13(3):314-21.

5. Rocha LB, Barreira IA. A enfermagem e a condição feminina: figuras-tipo de mulheres no Estado Novo. Esc Anna Nery. Rio de Janeiro. 2002 ago;6(2):229-40.

6. Mecone MCC, Freitas GF. Representações da enfermagem na imprensa da Cruz Vermelha Brasileira (1942-1945). Texto \& Contexto Enferm. Florianópolis. 2009 out/dez;18(4):741-9.

7. Cytrynowicz R. A serviço da pátria: a mobilização das enfermeiras no Brasil durante a Segunda Guerra Mundial. História, Ciências, Saúde-Manguinhos. Rio de Janeiro. 2000 maio/jun;7(1):73-91.

8. Oliveira AB, Santos TCF, Barreira IA, Almeida Filho AJ. As enfermeiras da Força Expedicionária Brasileira e a divulgação de seu retorno ao lar. Rev Latinoam Enferm. São Paulo. 2009 nov/dez;17(6).

9. Bernardes MMR, Lopes GT. Enfermeiras do Exército Brasileiro no transporte aéreo de feridos: um desafio enfrentado na $2^{\mathrm{a}}$ Guerra Mundial. Rev Bras Enferm. 2007 $\mathrm{jan} / \mathrm{fev} ; 60(1): 68-72$.

10. Oliveira $A B$. Signos do esquecimento: os efeitos simbólicos da participação das enfermeiras da Força Expedicionária Brasileira na Segunda Guerra Mundial (1943-1945) [dissertação]. Rio de Janeiro: Universidade Federal do Rio de Janeiro, Escola de Enfermagem Anna Nery; 2007. 156 p.

11. Oliveira AB, Santos TCF. Entre ganhos e perdas simbólicas: a (des)mobilização das enfermeiras que atuaram na Segunda Guerra Mundial. Esc Nery. 2007 set;11(3):423-8.

12. Bernardes MMR, Lopes GT. As enfermeiras da força expedicionária brasileira no front italiano. Rev Esc Enferm USP. 2007;41(3):447-53.

13. Bernardes MMR, Lopes GT, Santos TCF. A visibilidade da atuação de uma enfermeira do Exército Brasileiro a um ferido na $2^{a}$ Guerra Mundial. Rev Esc Enferm USP. 2005; 39(1):627.

14. Bernardes MMR, Lopes GT, Santos TCF. As enfermeiras na força expedicionária brasileira: a criação de um habitus militar na Segunda Guerra Mundial. Esc Anna Nery. 2004 dez;8(3):370-7.

15. Bernardes MMR, Lopes GT, Santos TCF. Base de sustentação militar de Vargas durante a $2^{a}$ guerra e a soberania bélica alemã: percepções de enfermeiras e militares. Texto \& Contexto Enferm. 2005 out/dez;14(4):544-50. 


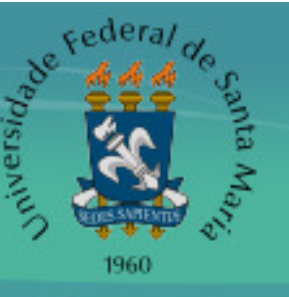

16. Oliveira AB, Santos TCF, Barreira IA, Lopes GT, Almeida Filho AJ, Amorim WM. Enfermeiras brasileiras na retaguarda da Segunda Guerra Mundial: repercussões dessa participação. Texto \& Contexto Enferm. 2009 dez;18(4):688-96.

17. Oliveira $A B$, Santos TCF. Condecorações de guerra como investidura de bens simbólicos às ex-enfermeiras febianas. Esc Anna Nery Rev Enferm. 2010 jan/mar;14(1):19-25.

18. Barreira IA, Baptista SS. A (re)configuraçäo do campo da enfermagem durante o Estado Novo (1937-1945). Rev Bras Enferm. 2002 mar/abr;55(2):205-16.

19. Bernardes MMR, Lopes GT, Santos TCF. Método analítico fotográfico oral: uma proposta inovadora em pesquisa histórica. Rev Enferm UERJ. 2003 set/dez;11(3): 353-8.

20. Araujo CA. Bibliometria: evolução histórica e questões atuais. Em Questão. 2006 jan/jun;12(1):11-32.

21. Moreira A, Porto F, Freitas GF, Campos PFS. Simpósio Ibero-Americano de história da enfermagem: novas perspectivas da produção intelectual em história da enfermagem. Rev Esc Enferm USP. 2009;43(esp 2):1358-63.

22. Padilha MICS, Borenstein MS. O método de pesquisa histórica em enfermagem. Texto \& Contexto Enferm. 2005 out/dez;14(4):575-84.

23. Aróstegui J. Pesquisa histórica: teoria e método. Bauru: EDUSC; 2006.

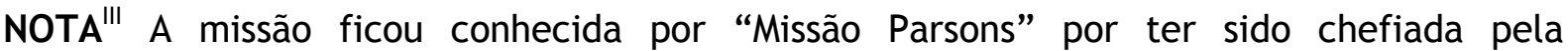
enfermeira norte-americana Ethel Parsons, que representava a principal liderança da Fundação Rockefeller no Brasil.

Data de recebimento: 08/08/2012

Data de aceite: 20/12/2012

Contato com autor responsável: Luciana Mendes Berlofi

Endereço: Rua Rondinha, n 92 apto 32. Chácara Inglesa. São Paulo - SP.

CEP: 04140-010

E-mail: luberlofi@bol.com.br 